\title{
Modeling of a Thermo-Electromagneto-Hydrodynamic Problem in Continuous Casting Tundish with Channel Type Induction Heating
}

\author{
Qiang WANG, ${ }^{1)}$ Baokuan $\mathrm{LI}^{1{ }^{*}}$ and Fumitaka TSUKIHASHI ${ }^{2)}$ \\ 1) School of Materials and Metallurgy, Northeastern University, Wenhua Road 3-11, Heping District, Shenyang, 110819 China. \\ 2) Department of Advanced Materials Science, Graduate School of Frontier Sciences, The University of Tokyo, 5-1-5 \\ Kashiwanoha, Kashiwa, Chiba, 277-8561 Japan.
}

(Received on June 28, 2013; accepted on September 25, 2013)

\begin{abstract}
A mathematical model has been developed to understand the electromagnetic phenomena, heat transfer and molten steel flow in a continuous casting tundish with channel-type induction heating. Maxwell equations are first solved using the finite element method to determine the electromagnetic force and joule heating. Then, the Navier-Stokes equations and energy conservation equation are also solved with the electromagnetic force and joule heating as a source term, respectively. The two-equation RNG $k-\varepsilon$ model is used to represent the turbulent mixing. Additionally, the tracer distribution is determined by solving a scale transport equation. The coupled flow field, temperature distribution and concentration distribution are solved by the finite volume method. A non-isothermal water model experiment is performed to observe significantly buoyancy driven flow in the tundish with induction heating. The results indicate that a current loop would be formed by the induced current through the two channels. The electromagnetic force points to the center of the channel generating a pinch effect on molten steel. As skin effect and proximity effect, the electromagnetic force as well as the joule heating in the region closer to the induction coil is greater than that in another region. Therefore, spiral recirculation would occur in the channels when molten steel flows through. After flows through the channels, the molten steel lifts upward under the effect of buoyancy. The heat loss of molten steel can be compensated effectively by the joule heating, and the temperature distribution become more uniform in the continuous casting tundish with induction heating.
\end{abstract}

KEY WORDS: induction heating; magnetohydrodynamics; heat transfer; tundish.

\section{Introduction}

The continuous casting tundish, working as a buffer and distribution of molten steel between the ladle and the continuous casting mold, plays a key role in affecting the quality and productivity as well as the performance of the continuous casting machine of molten steel. In order to obtain ideal fluid flow characteristics in tundish, various flow control devices, such as weirs, dams, and turbulence inhibitors, have been widely used in tundish. ${ }^{1-4)}$ All of them are designed to increase the mean residence time and plug flow volume of molten steel in tundish for enhancing inclusions removal rate which is good to the slab quality. However, the distribution of molten steel temperature is also very critical to the slab quality. The distribution of molten steel compositions would get more uniform if the temperature distribution improved in tundish. In addition, keeping constant casting temperature is in favor of the slab quality stability and reliability. Practical conditions of tundish in a steel plant are generally non-isothermal and this cannot be ignored.5) The non-isothermal nature of molten steel flows will occur due to heat losses that take place from the top surface of molten steel and from heat losses through the side walls and through the bottom of the tundish. Thus, the outlet temperature of molten steel drops significantly with the increasing of mean residence time which goes against continuous casting process. ${ }^{6}$ There are many situations in actual practice where

\footnotetext{
* Corresponding author: E-mail: libk@smm.neu.edu.cn
}

DOI: http://dx.doi.org/10.2355/isijinternational.54.311 the molten steel temperature in the tundish is non-uniform. Because of the increasing demands for high quality metallurgical production year by year, new engineering solutions are developed to eliminate the current drawbacks in the tundish. Recently a new technology such as tundish with induction heating has been proposed to improve the molten steel temperature distribution and keep a constant casting temperature in tundish during continuous casting process.

A tundish with channel type induction heating patent was proposed by Ueda et al., ${ }^{7}$ in 1983. In the patent, a tundish with a channeled induction-heating device at its sidewall was presented. The thermal loss of molten steel in the tundish can be compensated effectively. Mabuchi et al., ${ }^{8)}$ investigated the molten steel flow characteristics by performing the residence time distribution (RTD) in the tundish with induction heating. They found the molten steel as well as inclusions lifts upward under the effect of buoyancy due to the induction heating which is beneficial to the remove of inclusions. Umbrashko et al. ${ }^{9)}$ used the experiment and numerical simulation to study the turbulent flow in induction furnaces. The experimental measurements of the melt flow velocities were carried out in a laboratory induction crucible furnace, where Wood's metal is used as the model melt. In their numerical modeling, they compared different turbulent models first and then decided to use the LES turbulent model to simulate the melt flow. Vives and Ricou ${ }^{10)}$ used an experiment to study the multi-physical field within a cold four-tenth physical model of a $1300 \mathrm{~kW}$ channel induction furnace. Their key research contents were also the electromagnetic force and the velocity field in the channel 
induction furnace. According to their experimental results, the magnetic field lines on the horizontal cross-section of the channels were approximately concentric circular. The electromagnetic forces on the horizontal cross-section of the channels pointed to the central of the channels which gives rise to the classical "pinch effect". The melt flow structure is very complicate. The melt had a rotating velocity and the peak velocity was found in the corner region. Kenji et al. ${ }^{11)}$ used a magnetohydrodynamic calculation to investigate the flow field in a large molten-iron inductor which has a similar physical structure to the induction furnace in the Vives and Ricou's research. They investigated the melt flow field under different situations, and indicated that inductors have high performance to heat the melt and to make the circulation flows in their channels. They also calculated the melt flow field without and with joule heating and found that the electromagnetic force affects the flow field extremely more than the buoyancy do. Miura et al. ${ }^{12)}$ performed some industrial tests on the tundish with induction heating of No. 2 continuous caster at Yawata Works. The induction heating was used to keep the molten steel temperature around $1550^{\circ} \mathrm{C}$ at the later stage of the casting due to the molten steel temperature dropped sharply. They studied the change of cleanliness of the molten steel in the tundish with induction heating. With the help of the electromagnetic force and the buoyancy driven flow, the inclusion removal ratio was increased and the surface quality of slab was improved significantly.

From the above discussion, it should be noted that a number of researchers have included electromagnetic field, fluid flow, and inclusion behavior to analyze furnace or tundish with induction heating. Nonetheless, a little paper published focus on the temperature distribution of molten steel in the tundish with induction heating. As we know, the temperature distribution of molten steel in the tundish is very critical to slab quality. In addition, the primary purpose of induction heating is to make the temperature distribution more uniform and keep a constant casting temperature. Therefore, the temperature distribution should be paid enough attention in the research of tundish with induction heating.

The heat transfer phenomena in the conventional tundish have been widely investigated. Joo et al., ${ }^{13)}$ reported on the heat transfer phenomena and inclusion behavior in different structure tundish using mathematical model with non-isothermal conditions. In order to study the thermal natural convection phenomena, the molten steel density was assumed as a function of temperature instead of a constant. According to their numerical results, the net drop in temperature of molten steel for their conditions modeled was about $16 \mathrm{~K}$ which would make the natural convection currents significant in the tundish. The temperature drop cannot be changed even with weir or dam arrangements in the tundish, but only make the temperature distribution more uniform. Thus, it is essential to use the induction heating on the tundish to compensate the heat loss of molten steel. In addition, it has been shown by Joo et al. ${ }^{13)}$ and Chakraborty et $a l .{ }^{14)}$ that the fluid flow patterns developed in tundish with non-isothermal conditions can be quite different from those obtained under isothermal conditions. Non-isothermal conditions give rise to natural convection and buoyancy driven flows within a tundish that are of a comparable order of magnitude to the inertially-driven components. In the tundish with induction heating, the effect of natural convection and buoyancy driven flows would be even more significant because of the molten steel temperature rises dramatically. Thus, it is necessary to investigate the temperature distribution and the fluid flow of molten steel in the tundish with induction heating with non-isothermal conditions.

In present work, the joule heating and temperature distribution in tundish with induction heating was our research focus. The physical experiments were done in the equivalent one third scale plexiglass water model of a tundish with induction heating. Step input of hot water was introduced into the channel to simulate buoyancy driven flow induced by induction heating. Thermal gradient of the hot water was shown to have a significant effect on the fluid flow pattern. ${ }^{15,16)}$ A thermoelectromagneto-hydrodynamic mathematical model has been developed so as to investigate the electromagnetic field, flow field as well as heat transfer phenomena in tundish with induction heating. In present work, the non-isothermal water model experiment and the complete understanding of the molten steel temperature distribution in tundish with induction heating by mathematical model are really two novel aspects.

\section{Model Development}

\subsection{Geometrical Description}

The structure of a three-dimensional (3D) tundish with induction heating is shown in Fig. 1. The system is constructed based on a channel-type one-strand tundish. The tundish consists of two chambers such as receiving chamber and discharging chamber, which are connected by channels. The induction heating system is arranged between two channels consisting of induction coil, iron core, and the air coiling system which is not shown in Fig. 1. One-phase alternating current is applied by a $50 \mathrm{~Hz}$ frequency power source. Alternating current in the induction coil wound around the iron core generates an alternating magnetic field which in turn induces current in molten steel in the channels form a single-turn secondary coil. The induced current in the channels heats the molten steel by producing joule heating. In addition, the electromagnetic force resulted from the interaction between the induced current with the magnetic field acts primarily in channels.

\subsection{Physical Model}

Water model experiment is carried out in a one third scale water model of the tundish with hot water. Froude similarity criterion was used in order to satisfy the dynamic similarity. Figure 2 show the experimental setup which consists of a
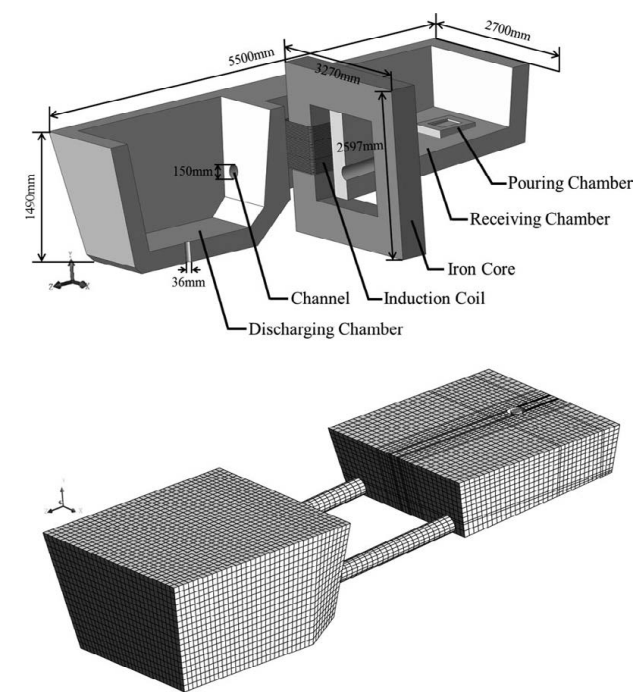

Fig. 1. Geometrical model of the tundish with the induction heating and the mesh.

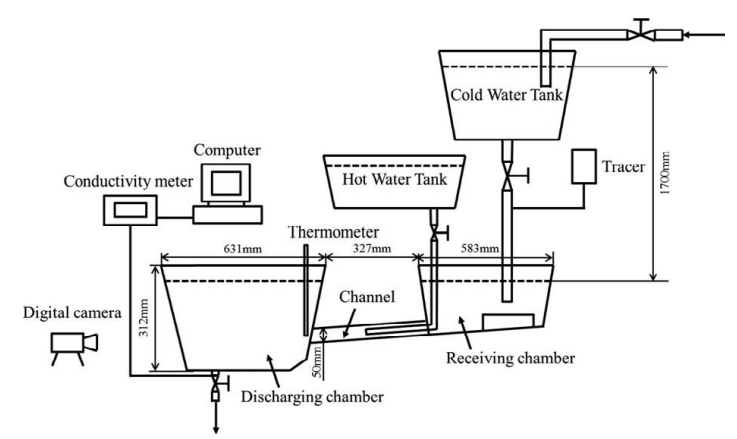

Fig. 2. Experimental system of the tundish with induction heating. 
Table 1. Process and physical parameters.

\begin{tabular}{cc}
\hline Parameter & Value \\
\hline Molten steel mass flow rate, $\mathrm{kg} / \mathrm{s}$ & 33.3 \\
Molten steel inlet temperature, $\mathrm{K}$ & 1833.15 \\
Molten steel electric conductivity, $\mathrm{S} / \mathrm{m}$ & $7.14 \times 10^{5}$ \\
Molten steel magnetic conductivity, $\mathrm{H} / \mathrm{m}$ & $1.257 \times 10^{-6}$ \\
Molten steel density, $\mathrm{kg} / \mathrm{m}^{3}$ & $8523-0.8358 \mathrm{~T}$ \\
Molten steel viscosity, $\mathrm{Pa} \cdot \mathrm{s}$ & 0.0061 \\
Molten steel thermal conductivity, $\mathrm{W} / \mathrm{m} \cdot \mathrm{K}$ & 41 \\
Molten steel specific heat, $\mathrm{J} / \mathrm{kg} \cdot \mathrm{K}$ & 750 \\
Induction coil current frequency, $\mathrm{Hz}$ & 50 \\
\hline
\end{tabular}

Table 2. Densities of the molten steel and the water.

\begin{tabular}{cc}
\hline Material & Density, $\mathrm{kg} / \mathrm{m}^{3}$ \\
\hline Molten steel & $8523-0.8358 \mathrm{~T}$ \\
Water & $654.619+2.5446 \mathrm{~T}-0.004683 \mathrm{~T}^{2}$ \\
\hline
\end{tabular}

plexiglass glass tundish, water supply, the electric conductivity meter, tracer injection system and the hot water injection system. ${ }^{5)}$ The temperature of water in tundish is around 293.15 K for all experiments. A hot water tank is placed beside the tundish. The hot water is injected into the middle of the channel and then mixed with the existing water. Thus the water temperature at the channel outlet would be increased just like the effect of the induction heating. The densities of molten steel and water are shown in Table 2. It can be inferred that the density difference of the molten steel between $1833.15 \mathrm{~K}$ and $1870.15 \mathrm{~K}$ is approximately equal to that of the water between $293.15 \mathrm{~K}$ and $355.15 \mathrm{~K}$. The same density difference can achieve the similar buoyancy driven flow. ${ }^{5)}$ Therefore, the flow rate of the hot water is adjusted to ensure the temperature at the outlets of channels in the water model experiment. In experiment, the flow rate and the temperature of cold water are approximate $2 \mathrm{~kg} / \mathrm{s}$ and $293.15 \mathrm{~K}$, respectively. In order to reach the temperature at the channel outlet we expect, the flow rate and temperature of hot water is set as $6.89 \mathrm{~kg} / \mathrm{s}$ and $373.15 \mathrm{~K}$ approximately. In addition, the heat loss of water in experiment is very small and ignored due to the experiment time is short. On the other hand, the induction heating power is assumed to be $1200 \mathrm{~kW}$ in the corresponding calculation so as to ensure the same density difference. The black ink is used for flow visualization and photography. In addition, the curves of resident time distribution (RTD) ${ }^{17-20)}$ is also measured by the stimulus-response-technique which used to validate the mathematical model.

\subsection{Mathematical Model}

\subsubsection{Electromagnetic Model}

According to Maxwell equations, the induced current density is defined as:

$$
\vec{J}=\sigma[\vec{E}+(\vec{u} \times \vec{B})]
$$

Magnetic induction is used for magnetic flux density calculation as follows:

$$
\frac{\partial \vec{B}}{\partial t}=\nabla \times(\vec{u} \times \vec{B})+\frac{1}{\sigma \mu} \nabla^{2} \vec{B}
$$

The magnetic Reynolds number is expressed as:

$$
\operatorname{Re}_{m}=\frac{u_{0} L_{0}}{v_{m}}, \text { and } v_{m}=\frac{1}{\sigma \mu}
$$

where $u_{0}$ is characteristic velocity, $L_{0}$ is characteristic length, $\sigma$ is conductivity, $\mu$ is permeability. The magnetic Reynolds number indicates the ratio of magnetic convection and magnetic diffusion. In present work, the main influenced region of magnetic field in tundish is the channels. In the channels, the maximum velocity of molten steel is less than $0.3 \mathrm{~m} / \mathrm{s}$. Therefore, the maximum magnetic Reynolds number is less than 0.04. It means that the effect of the magnetic convec- tion is much less than that of the magnetic diffusion. Therefore, the effect of fluid flow on the electromagnetic field can be neglected. Consequently, the induced current density $\vec{J}$ and the magnetic induction equation can be simplified as: ${ }^{21}$ )

$$
\begin{aligned}
\vec{J} & =\sigma \vec{E} \\
\frac{\partial \vec{B}}{\partial t} & =\frac{1}{\sigma \mu} \nabla^{2} \vec{B}
\end{aligned}
$$

The magnetic vector potential is introduced in present work as follows:

$$
\vec{B}=\nabla \times \vec{A}, \text { and } \vec{E}=-\frac{\partial \vec{A}}{\partial t}-\nabla \vec{V}
$$

Hence, the Eq. (5) results in a diffusion equation in terms of vector potential $\vec{A}$, which is expressed as follows:

$$
\frac{\partial \vec{A}}{\partial t}=\frac{1}{\sigma \mu} \nabla^{2} \vec{A}
$$

The joule heating power density resulted from an interaction of induced current and molten steel is expressed by:

$$
\vec{\omega}=\frac{Q_{J}}{t}=\frac{\left(\vec{J}^{2} / \sigma\right) t}{t}=\sigma \vec{E}^{2}
$$

The electromagnetic force can be decomposed into a time-dependent component and a time-independent component when the harmonic electromagnetic field is considered. Numerical studies on the electromagnetically driven flow show that the alternating current period which control the variation period of the electromagnetic field is much shorter than the momentum response time of the liquid metal if its frequency is larger than $5 \mathrm{~Hz}^{22}$ ) Therefore, the time-averaged electromagnetic force is expressed as follows:

$$
\vec{F}_{m}=\frac{1}{2} \operatorname{Re}\left(\vec{J} \times \vec{B}^{*}\right)
$$

where $\vec{B}^{*}$ is the conjugate complex number of $\vec{B}$, Re is the real part of a complex quantity, $\vec{u}$ is molten steel velocity, $\vec{B}$ is magnetic flux density, $\vec{E}$ is the electric field intensity, $\vec{J}$ is induced current density, $\vec{A}$ is magnetic vector potential, $\vec{V}$ is electric potential and $t$ is the time.

\subsubsection{Fluid Dynamics Model}

In present work, the equation of mass continuity and the Navier-Stokes equation for molten steel are expressed, respectively, as follows:

$$
\begin{array}{r}
\frac{\partial \rho}{\partial t}+\nabla \cdot(\rho \vec{u})=0 \\
{\left[\frac{\partial(\rho \vec{u})}{\partial t}+\nabla \cdot(\rho \vec{u} \times \vec{u})\right]=-\nabla p+\mu_{e f f} \nabla^{2} \vec{u}+\rho \vec{g}+\vec{F}_{m}}
\end{array}
$$

where $\rho$ is molten steel density, $\vec{g}$ is gravitational acceleration vector, $\mu_{e f f}$ is effective viscosity, $p$ is pressure and $\vec{F}_{m}$ is the volumetric force..$^{23,24)}$

The term $\rho \vec{g}$ in Eq. (11) accounts for the buoyancy acting on the hotter or cooler molten steel. In many papers, ${ }_{5,11)}$ the buoyancy has been simplified by using a Boussinesq's model which is just appropriate for the small temperature difference. However, the difference between the maximum and the minimum temperature of the molten steel in the tundish with induction heating would reach as high as $50 \mathrm{~K}$. In order to describe the buoyancy driven flow more accuracy, the molten steel density would be treated as a function of the temperature which is expressed as: $:^{25,26)}$

$$
\rho=8523-0.8358 T
$$

The term $\vec{F}_{m}$ in Eq. (11) represents the volumetric electromagnetic force resulting from the interaction between the induced current with the magnetic field. The electromagnetic force would be calculated by the commercial software 
ANSYS and then introduced into CFX as a source term by a user defined program.

A large curvature streamline of molten steel would be formed under the effect of tundish structure and electromagnetic force. Therefore, the two-equation RNG $k-\varepsilon$ turbulent model which considers the effect of swirl on turbulence is adopted to determine the effective viscosity $\mu_{e f f .}{ }^{27,28)}$

To simulate the tracer dispersion, a scale transport equation is considered.

$$
\frac{\partial(\rho \varphi)}{\partial t}+\nabla \cdot(\rho \vec{u} \varphi)=\nabla \cdot\left(\left(\rho D_{\phi}+\frac{\mu_{t}}{S c_{t}}\right) \nabla \varphi\right) \ldots .
$$

A user defined non-dimensional scalar $\varphi$ is considered at the inlet of tundish. $S c_{t}$ is the turbulence Schmidt number. The kinematic diffusivity $D_{\phi}$ of the scalar in the molten steel is assumed to be very low $\left(10^{-5} \mathrm{~m}^{2} \mathrm{~s}^{-1}\right)$. The value of the scalar at the inlet is maintained as unity throughout the time of the calculation. The movement of the tracer with time is monitored and compared with those obtained from the water model experiment.

\subsubsection{Heat Transfer Model}

Energy conservation equation is expressed as:

$$
c_{p}\left[\frac{\partial(\rho T)}{\partial t}+\nabla \cdot(\rho T \vec{u})\right]=\nabla \cdot\left(\lambda_{\text {eff }} \nabla T\right)+S_{T}+Q
$$

where $T$ is temperature, $c_{p}$ is specific heat considering as a constant, $\lambda$ is thermal conductivity which is controlled mainly by turbulence level through turbulent viscosity:

$$
\lambda_{\text {eff }}=\lambda_{0}+\frac{c_{p} \mu_{t}}{\operatorname{Pr}_{t}}
$$

$\mu_{t}$ is turbulent viscosity calculated by the RNG $k-\varepsilon$ turbulent model, $\operatorname{Pr}_{t}$ is turbulent Prandtl number (with a value of 0.7 ). $S_{T}$ is viscous dissipation and $Q$ is other volumetric heat sources such as joule heating in present work. ${ }^{29,30)}$ The temperature distribution is coupled with the velocity field through the buoyancy term in Eq. (11).

\subsubsection{Boundary Conditions}

In present work, one-phase alternating current is applied on induction coil by a $50 \mathrm{~Hz}$ frequency power source in the calculation of the electromagnetic field. In order to understand the tundish with induction heating more deeply, three different input powers are considered. The air surfaces should be set with the magnetic flux parallel condition.

Mass flow rate is set for the inlet and the outlet of tundish with a turbulent intensity of $10 \%$. Zero shear stress boundary condition is applied for the free surface of tundish. As for the other wall, no-slip condition is used. In order to capture the dramatic change of gradients accurately, the standard wall functions near the wall are adopted. In addition, the walls and free surface of the tundish are assumed to be impervious to the tracer, i.e. zero flux condition is considered at the walls and free surface for the defined scalar. The inlet temperature of molten steel is fixed to the casting temperature.

The heat loss from each wall of the tundish is very important to the calculation of temperature distribution. The temperature drop of the molten steel in tundish can research 16 $\mathrm{K}$ because of the huge heat loss. ${ }^{13}$ ) Since the temperature distribution of the molten steel in tundish with induction heating is the focus in present work, it is necessary to consider the heat loss from each wall of the tundish. In the calculation, the second boundary condition is used. The ways of heat loss in the tundish include the radiation and convection which would be converted into the heat flux at each wall. According to references, ${ }^{31-34)}$ the heat flux at the top surface, the bottom, the longitudinal walls, the transversal walls, and the channel walls is $15 \mathrm{~kW} / \mathrm{m}^{2}, 1.8 \mathrm{~kW} / \mathrm{m}^{2}, 5.2 \mathrm{~kW} / \mathrm{m}^{2}, 4.6 \mathrm{~kW} / \mathrm{m}^{2}$, and $2.0 \mathrm{~kW} / \mathrm{m}^{2}$, respectively. Values of other parameters used in the model calculation are listed in Table $\mathbf{1}$.

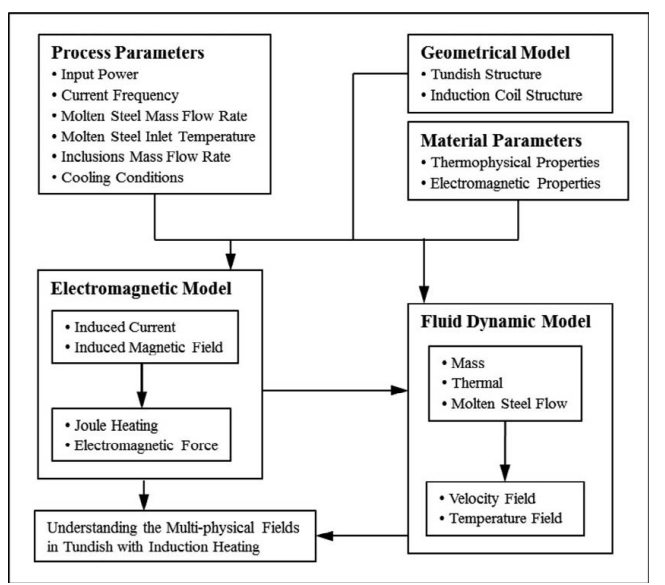

Fig. 3. A flow diagram showing the model requirement for the calculation.

\section{Solution Method}

A flow diagram showing the modeling requirements for calculation is shown in Fig. 3. The strategy adopted here is a sequential approach. Firstly, the steady 3D magnetic diffusion equation with the electromagnetic field of induction heating is solved in order to carry out the coupled simulation. Secondly, the steady flow field and the temperature distribution of molten steel in tundish without induction heating are calculated as the initial field for next calculation. Thirdly, the transient flow field and the temperature distribution of molten steel in tundish with induction heating are computed by adding the joule heating to energy conservation equation and the electromagnetic force to momentum conservation equation for molten steel as the source terms. ${ }^{35,36)}$

The governing equations of electromagnetic field and other physical fields are solved by employing the commercial software ANSYS and CFX, respectively. As for the electromagnetic field calculation based on ANSYS, the finite element method is used. The fluid flow field and temperature distribution are calculated by finite volume method based on CFX. The discretization step of computation domain in electromagnetic field calculation is determined by considering the penetration depth of an electromagnetic wave in the melt region. In addition, since it is difficult to keep the consistency of the two sets of grids used in electromagnetic calculation and flow dynamic calculation, the joule heating distribution and the electromagnetic force field should be interpolated accurately between the two sets of grids. The number of hexahedron elements used in the electromagnetic calculation, the flow and heat transfer calculation is about 1150000 and 1020000 respectively. During each iteration, the convergence is assumed to be reached if all the normalized unscaled residuals are less than $10^{-6}$.

\section{Validation of the Mathematical Model against Experimental Results}

In present work, mathematical model has been performed to study the electromagnetic field, fluid flow, and heat transfer phenomena in a tundish with induction heating. It is necessary to validate the mathematical model with corresponding experiment. In this section, the experimental validation of the mathematical model is established with the experiment data reported in the literature and the water model results. In Vives and Ricou's ${ }^{10}$ ) experiment, the electromagnetic field in a four-tenth scale physical model of a $1300 \mathrm{~kW}$ channel induction furnace which structure is similar to the tundish with induction heating in present work. The same current density and frequency are applied on the tundish with induction heating in present work. Figure 4 show the predicated magnetic flux density field and the electromag- 


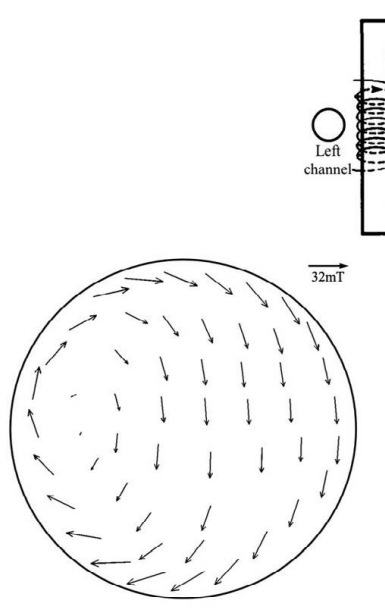

(a)

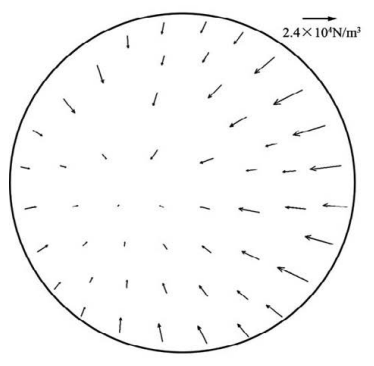

(c)

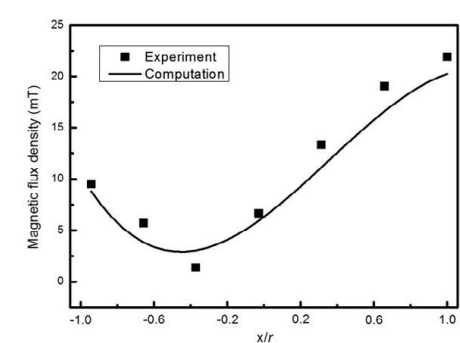

(b)

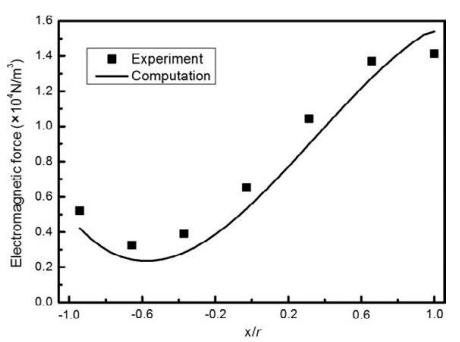

(d)
Fig. 4. Validation of the electromagnetic model. (a) Predicated magnetic flux density field in the left channel. (b) Comparison of magnetic flux density at the horizontal axis. (c) Predicated Electromagnetic force field in the left channel. (d) Comparison of electromagnetic force at the horizontal axis.

netic force field in the left channel. We can find that the distribution of predicated magnetic flux density field and electromagnetic force field is very similar with experimental results. Besides, Figs. 4(b) and 4(d) shows the comparison of magnetic flux density and electromagnetic force at the horizontal axis of left channel. It is easy to see that the value of magnetic flux density and electromagnetic force predicated is lesser than that measured in the experiments. The two primary coils in the experiments can responsible for the difference. The magnetic field induced by one coil would affect that induced by another coil. The two magnetic fields would be reinforced by each other because of the same direction. Thus, the measured results would greater than the numerically predicated results. The Figs. 5(a) and 5(b) compares the numerically predicated and experimentally observed tracer dispersion behavior in the tundish without and with induction heating. It is obvious to see that the profiles of the wave fronts are pretty similar. The minor differences at the outline edge can be attributed to the highly statistical nature of turbulent flow. In present work, the RNG $k-\varepsilon$ two-equation turbulent model is used to simulate the fluid flow which cannot predicate the random eddies. The large eddy simulation or the direct numerical simulation may perhaps eliminate the minor differences due to they are able to predicate these random eddies. However, the results are very similar and the mathematical model is robust. Figure 5(c) provides the comparison of the RTD curves between the numerically predicated and the experimentally in the tundish without induction heating. The dimentionless is time defined as:

$$
\theta=\frac{t}{\tau}, \text { and } \tau=\frac{V}{Q_{m}}
$$

The dimentionless concentration is defined as:

$$
E=\frac{C \tau}{\int_{0}^{\infty} C d t}
$$

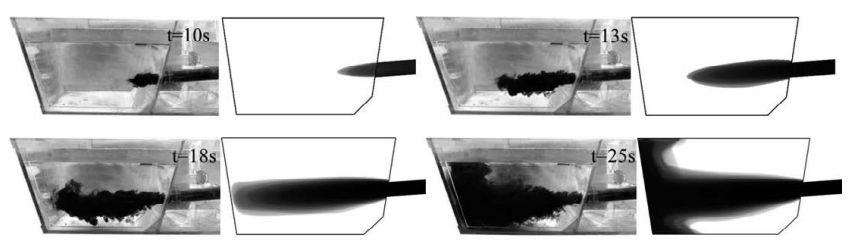

(a)

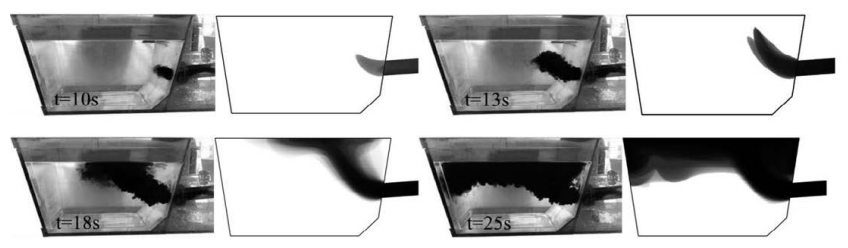

(b)

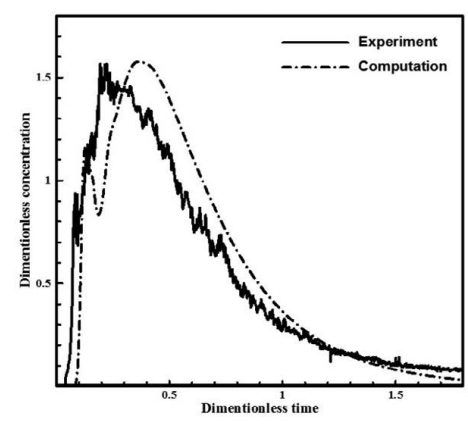

(c)

Fig. 5. Validation of the flow and heat transfer model. (a) Flow pattern in tundish without induction heating. (b) Flow pattern in tundish with induction heating. (c) RTD curve in tundish without induction heating.

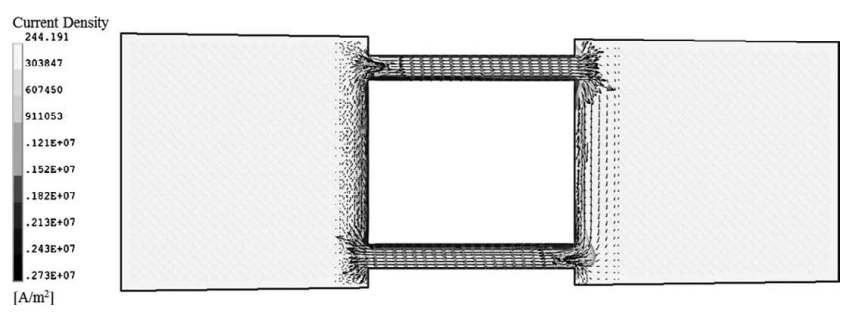

Fig. 6. Current density distribution at cross section of the tundish with $800 \mathrm{~kW}$ induction heating power.

where $t$ is the time, $\tau$ is the theoretical residence time, $V$ is the water volume in plexiglass glass tundish, $Q_{m}$ is the volumetric flow rate, and $C$ is the concentration. ${ }^{19)}$ The numerically predicated RTD curve is pretty similar $( \pm 15 \%)$ to that obtained from the experimental measurement. The RTD curve is not measured in the tundish with induction heating limited by the experimental conditions. Therefore, the mathematical model developed in presented validated both qualitatively and quantitatively.

\section{Results and Discussions}

\subsection{Electromagnetic Field}

Figure 6 shows the induced current density field at the cross section of the tundish with induction heating. The induced current distributes at the channels and the region of two chambers near the induction coil mainly. A current loop is formed by the induced current through the channels. Due to the skin effect and the proximity effect, the induced current on the side of channels closer to the induction coil is greater than that on the other side of channels. In addition, the current field at the corner regions, where the channels connect with the discharging chamber and the receiving chamber, is greater than other region. This phenomenon is also observed in Vives and Ricou's ${ }^{10)}$ experiments. The interaction of induced current with molten steel produces 


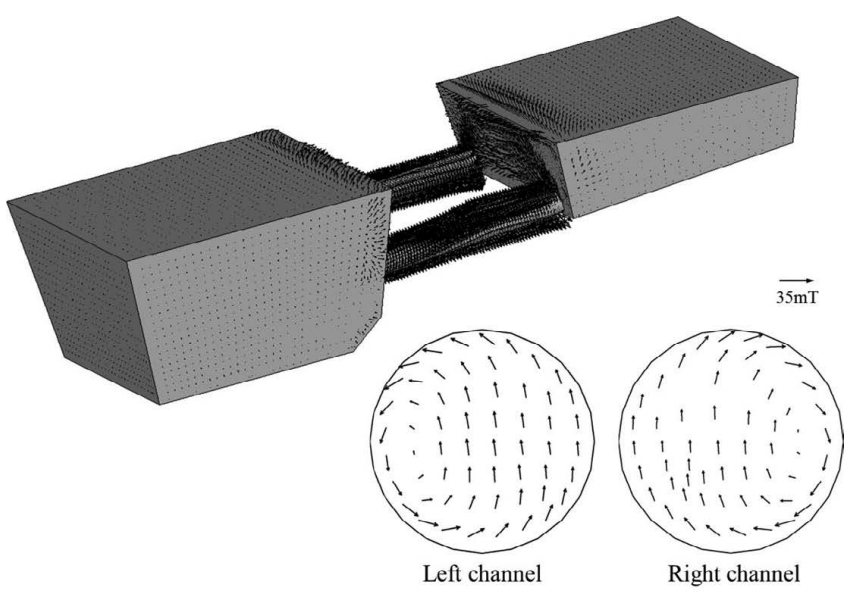

(a)

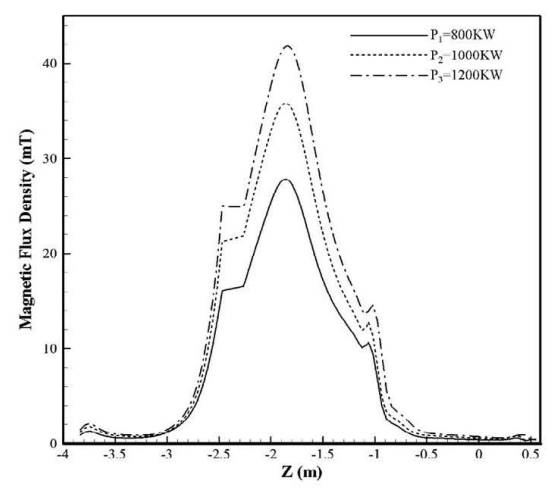

(b)

Fig. 7. Magnetic field. (a) Magnetic flux density in tundish with $800 \mathrm{~kW}$ induction heating power. (b) Magnetic flux density at the line formed by the meeting of cross section and vertical section with different induction heating power.

joule heating which would heat molten steel. Moreover, the electromagnetic force would be generated due to the interaction of magnetic field with induced current.

The magnetic flux density field in tundish with $800 \mathrm{~kW}$ induction heating power is shown in Fig. 7(a). The magnetic flux density in the channels and the region of two chambers near the induction coil is much greater than the other region. The magnetic field in the channels is a rotating magnetic field. Due to the effect of the asymmetrical induced current, the magnetic flux density is also presented as asymmetrical. Figure 7(b) shows the magnetic flux density at the line by the meeting of cross section and vertical section. The coordinate range of the channels is $-2.323 \mathrm{~m}$ to $-1.062 \mathrm{~m}$. The magnetic flux density reaches the maximum value in the channels. Besides, with the increasing induction heating power, the magnetic flux density in the channels also turns greater. On the contrary, the magnetic flux density does not change much. Furthermore, it is seen in Fig. 9 that the change of the magnetic flux density is very smooth, except for the corner regions where the current density changes dramatically.

Figure 8 shows the electromagnetic force field in the tundish with $800 \mathrm{~kW}$ induction heating power. The electromagnetic force in the channels is much greater than that in the other regions. The main influenced region of electromagnetic force is located in the channels as well as the two chambers near induction coil. The electromagnetic force points to the center of channels which would generate a pinch effect on the molten steel. Therefore, the molten steel would be extruded by the electromagnetic force when flows past the channels. In addition, because the asymmetrical distribution of induced current and magnetic field, the electromagnetic force field is also asymmetrical. The electromagnetic force on the side closer to the induction coil is greater than

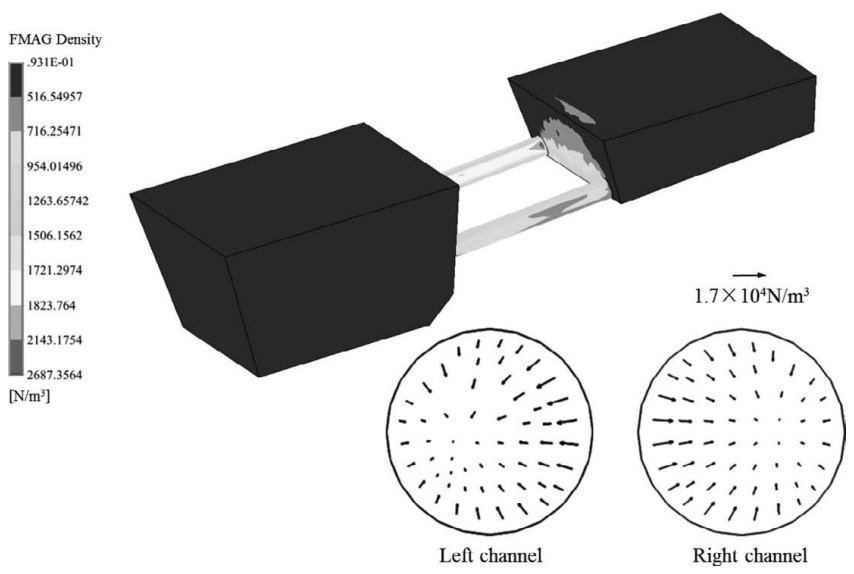

Fig. 8. Electromagnetic force field in the tundish with $800 \mathrm{~kW}$ induction heating power.

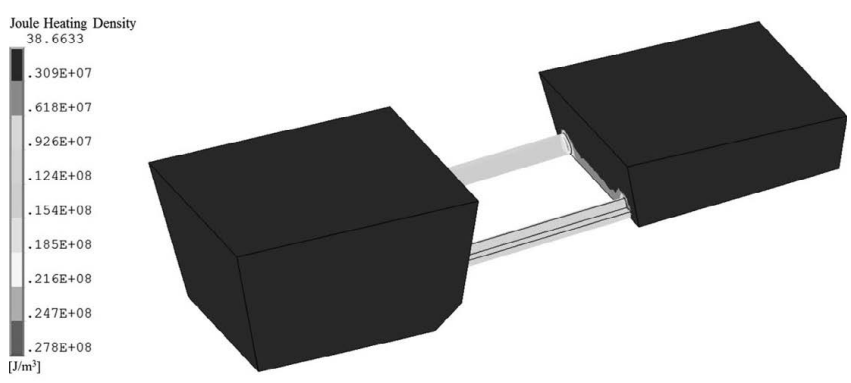

(a)

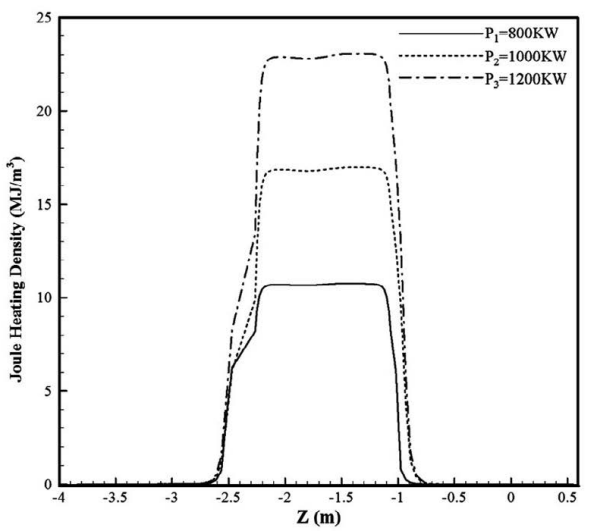

(b)

Fig. 9. Joule heating. (a) Joule heating density distribution in tundish with $800 \mathrm{~kW}$ induction heating power. (b) Joule heating density at the line formed by the meeting of cross section and vertical section with different induction heating power.

that on the other side. Hence, the molten steel would be acted by an off-centre force when flows past the channels.

\subsection{Joule Heating Density Distribution}

The distribution of the joule heating density in the tundish with $800 \mathrm{~kW}$ induction heating power is shown in Fig. 9(a). Because the joule heating is produced by the induced current, the distribution of the joule heating density is roughly as same as that of the induced current density field. Most joule heating distributes in the channels which would heat the molten steel rapidly when the molten steel flows past the channels. The joule heating at the periphery of the channels is greater than that at the center of the channels. Figure 9(b) shows the joule heating density at the line by the meeting of cross section and vertical section. With the increasing induction heating power, the joule heating density distributes in the channels becomes much greater. As for other regions, the joule heating density does not change much.

The distribution of the joule heating density under differ- 
ent induction heating power is very critical to the metallurgical characteristics of the tundish with induction heating. An application of the tundish with induction heating is reported in Miura's ${ }^{12)}$ paper. During the late stage of the casting and the process of the ladle changing, the molten steel temperature drops dramatically. Thus, the tundish with induction heating is adopted to compensate the heat loss of the molten steel. According to the rate of the heat loss, the induction heating power is adjusted in order to keep a constant casting temperature.

\subsection{Velocity Field}

Figure 10 shows the numerically predicated flow field of molten steel in the tundish without and with induction heating. In the tundish without induction heating, the molten steel flows past the channels and then flows downward under the effect of gravity which can be observed clearly in Fig. 10(a). Then the molten steel impinges the front wide wall and the bottom of the discharging chamber directly which may cause serious erosion of the inner lining refractory. Most molten steel flows out of the tundish directly and thus causes the obvious short-circuit flow. Only small part of the molten steel lifts upward at a very low velocity leading to a dead zone in the top region of the discharging chamber.

The numerically predicated flow field of molten steel in the tundish with induction heating gives rise to an obvious change as shown in Fig. 10(b). The molten steel is accelerated when flows past the channels under the combined effect of the electromagnetic force and gravity. In addition, because of the joule heating, the molten steel has a higher temperature than the surrounding molten steel after flows past the channels. Therefore, the molten steel lifts upward after flows past the channels with the help of buoyancy. The
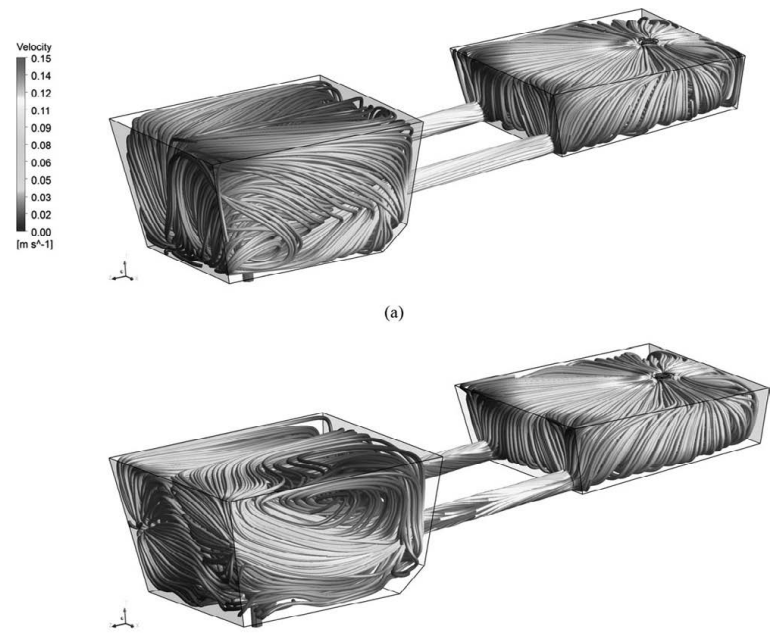

(b)

Fig. 10. Streamline of the molten steel in the tundish. (a) Without induction heating. (b) With $800 \mathrm{~kW}$ induction heating power.

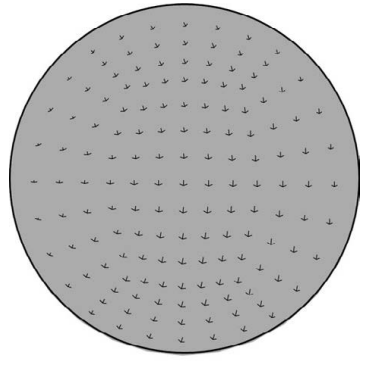

(a)

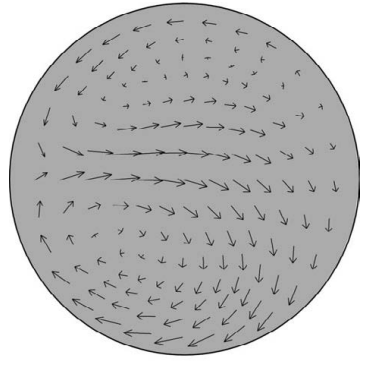

(b)
Fig. 11. Velocity field at vertical section of channel. (a) Without induction heating; maximum velocity is $0.1621 \mathrm{~m} / \mathrm{s}$. (b) With $800 \mathrm{~kW}$ induction heating power; maximum velocity is $0.1954 \mathrm{~m} / \mathrm{s}$. buoyancy driven flow can avoid the impact on the front transversal wall of the discharging chamber. When the molten steel reaches the top region, it would spiral down slowly and then flow out from the outlet. This motion mode of molten steel can reduce the short-circuit flow effectively and prolong the mean residence time which provide more opportunities for inclusions to float up.

Figure 11 shows the velocity at the vertical section of the channels in the tundish without induction heating and with induction heating. With induction heating, because of the off-centre force, the molten steel has a rotating velocity which would form a recirculation in the channels. Both the distribution and the order of magnitude of the numerically predicated velocity field are roughly as same as the measured velocity in Vives and Ricou's ${ }^{10)}$ experiments. The molten steel would be mixed intensely in the channels because of the rotating velocity.

\subsection{Temperature Distribution}

The primary purpose of induction heating is to compensate the heat loss of the molten steel and improve the temperature distribution. Hence, the temperature distribution in tundish without and with induction heating would be investigated deeply. In present work, the influence of the induction heating power on the temperature distribution is also investigated.

\subsubsection{Temperature Distribution in Tundish without Induc-} tion Heating

A large drop in the molten steel temperature occurs in the tundish without induction heating as shown in Fig. 12. The molten steel near the wall has more heat loss than the molten steel in the inner region. Therefore, the temperature of molten steel in the region near the wall is lower than that in the inner region. Besides, a low temperature region appears in the upper right of the discharging chamber due to the combined effect of the dead zone and the huge heat loss.

The molten steel flows to the bottom of the discharging chamber at first as shown in Fig. 13(a). Thus, the temperature of the molten steel in the lower region is higher than that in the upper region at first. However, as time goes on, the temperature of the molten steel in the lower region also reduces. The pathlines of the molten steel stream out from the channels in the discharging chamber move up slightly which can be observed clearly in Figs. 13(b) and 13(c). A dead zone is also formed in the lower region which reinforces the heat loss. The Fig. 12(c) shows the stable state of the temperature distribution. Low temperature region appears obviously in the upper region and the lower region which goes against the molten steel compositions uniformity.

The outlet temperature calculated in the tundish without induction heating is $1824.03 \mathrm{~K}$. The net drop in temperature

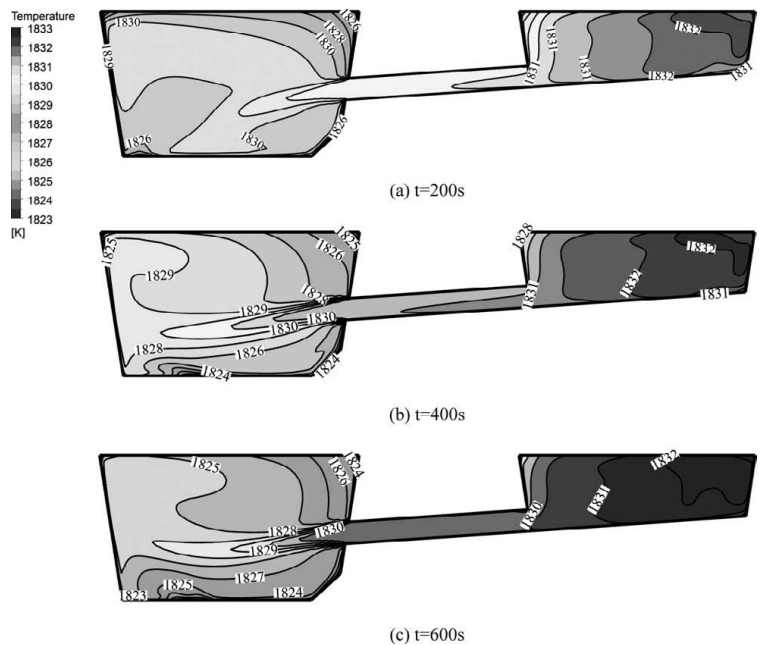

Fig. 12. Temperature distribution at the vertical section of tundish without induction heating. 


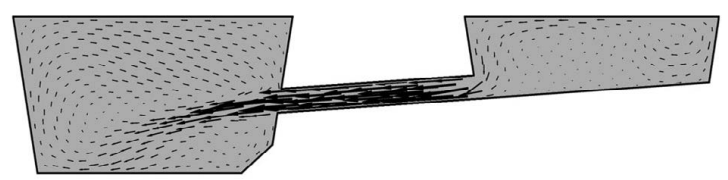

(a) $\mathrm{t}=200 \mathrm{~s}$

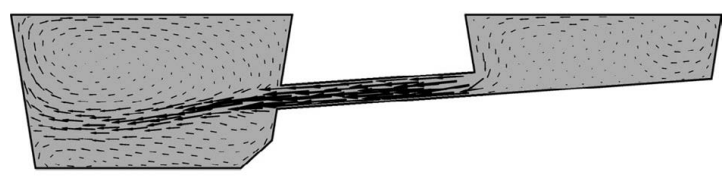

(b) $\mathrm{t}=400 \mathrm{~s}$

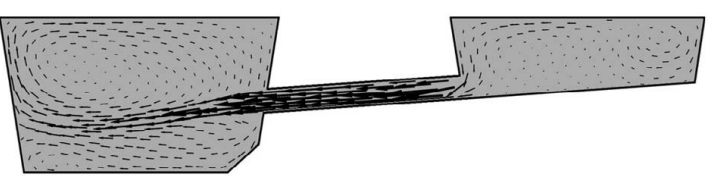

(c) $\mathrm{t}=600 \mathrm{~s}$

Fig. 13. Velocity field at the vertical section of tundish without induction heating; maximum velocity is $0.1723 \mathrm{~m} / \mathrm{s}$.

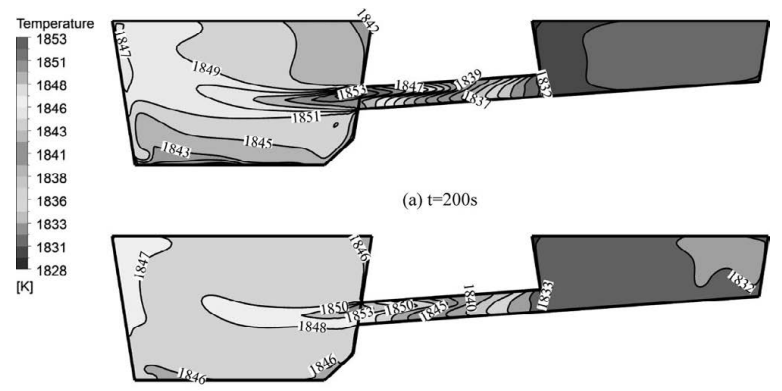

(b) $\mathbf{t}=400 \mathrm{~s}$

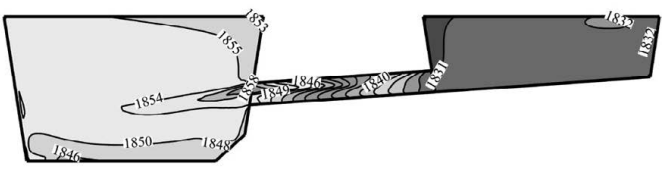

(c) $\mathrm{t}=600 \mathrm{~s}$

Fig. 14. Temperature distribution at the vertical section of tundish with $800 \mathrm{~kW}$ induction heating power.

for the conditions modeled is about $9.12 \mathrm{~K}$ which is disadvantage to the continuous casting process.

\subsubsection{Temperature Distribution in Tundish with $800 \mathrm{~kW}$ Induction Heating Power}

Figure 14 shows the temperature distribution in the tundish with $800 \mathrm{~kW}$ induction heating power. Because of most joule heating distributes in the channels, the molten steel would be heated rapidly when flows past the channels. Therefore, the temperature rises from $1832 \mathrm{~K}$ to $1853 \mathrm{~K}$. The temperature of the molten steel stream out from the channels is higher than that of surrounding molten steel. The molten steel stream out from the channels would lifts upward under the effect of buoyancy as shown in Fig. 15(a). The temperature of the molten steel in the upper region rises first and then the high temperature region expands downward gradually. As time goes on, the high temperature region takes over most region of the discharging chamber except the upper right region and the low right region which can be observed obviously in Fig. 14(c). Thus, the effect of the buoyancy driven flow turns weak leading to the pathlines of the molten steel stream out from the channels move down slightly. Figure 15(c) shows the stable state velocity field in tundish with $800 \mathrm{~kW}$ induction heating power. Due to the temperature distribution in the discharging chamber improved, the flow field gets more active.

The outlet temperature of molten steel is $1846 \mathrm{~K}$ which can be controlled accurately with the help of induction heat-

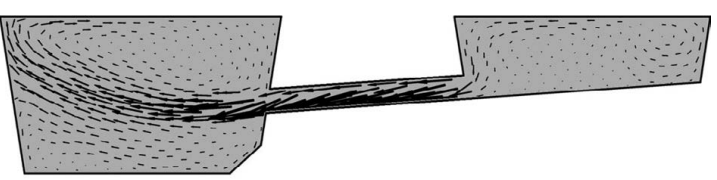

(a) $\mathrm{t}=200 \mathrm{~s}$

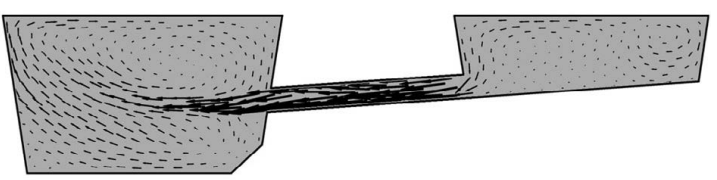

(b) $\mathrm{t}=400 \mathrm{~s}$

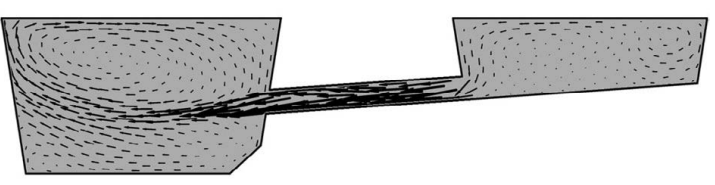

(c) $\mathrm{t}=600 \mathrm{~s}$

Fig. 15. Velocity field at the vertical section of tundish with $800 \mathrm{~kW}$ induction heating power; maximum velocity is $0.2047 \mathrm{~m} / \mathrm{s}$.

ing. It is easier to keep casting temperature constant which is beneficial to the slab quality.

\subsubsection{Temperature Distribution in Tundish with $1000 \mathrm{~kW}$ Induction Heating Power}

Figure 16 shows the temperature distribution in the tundish with $1000 \mathrm{~kW}$ induction heating power. Figure 17 shows velocity field in the tundish with $1000 \mathrm{~kW}$ induction heating power. The molten steel stream out from the channels also lifts upward just as same as the flow field in the tundish with $800 \mathrm{~kW}$. However, the temperature of the molten steel stream out from the channels is higher than that in the tundish with $800 \mathrm{~kW}$ induction heating power. Therefore, the buoyancy driven flow plays a more important role. The effect of buoyancy forces becomes more significant if the thermal gradient turns greater. On the other hand, the density of molten steel in the upper region of the discharging chamber is much less than that in the lower region. A strong natural convection is generated due to the high density difference which enhances the uniformity of the temperature distribution.

The high temperature region would expand downward with time. The change of the temperature distribution in turn affects the flow field. The fluid flow in the lower region gets more active. The velocity of the molten steel in the lower region at the time of $600 \mathrm{~s}$ is greater than that at the time of 200 s. Figure 16(c) shows the stable state temperature distribution in the tundish with $1000 \mathrm{~kW}$ induction heating power. The low temperature region in the discharging chamber is also the upper right region and the low right region.

\subsubsection{Temperature Distribution in Tundish with $1200 \mathrm{~kW}$ Induction Heating Power}

Figure 18 shows the temperature distribution in the tundish with $1200 \mathrm{~kW}$ induction heating power. Figure 19 shows velocity field in the tundish with $1200 \mathrm{~kW}$ induction heating power. The temperature distribution and the flow field in the tundish with $1200 \mathrm{~kW}$ induction heating power are almost as same as that in the tundish with $1000 \mathrm{~kW}$ induction heating power. The natural convection turns stronger in the tundish with $1200 \mathrm{~kW}$ induction heating power. Therefore, the high temperature region expands downward more quickly. The temperature of the molten steel in most region of the discharging chamber becomes very uniform at the time of $400 \mathrm{~s}$.

The low temperature region in the discharging chamber is also the upper right region and the low right region which is just as same as the all cases presented above. The low temperature region only turns small with the increasing of the induction heating power. Therefore, the weir and dam arrangements should be taken into consideration when the tundish with induction heating is applied into practical application. 


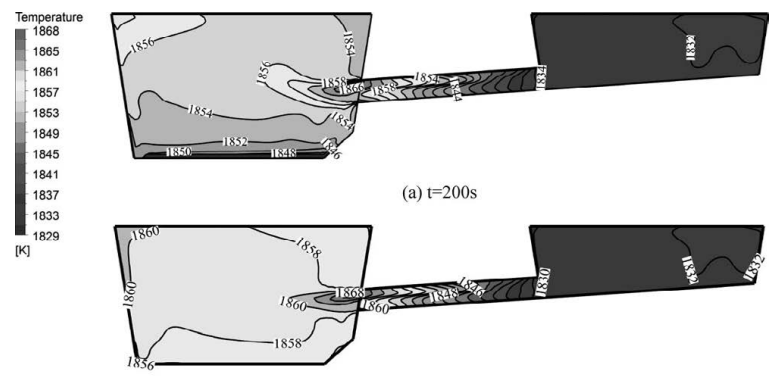

(b) $\mathrm{t}=400 \mathrm{~s}$

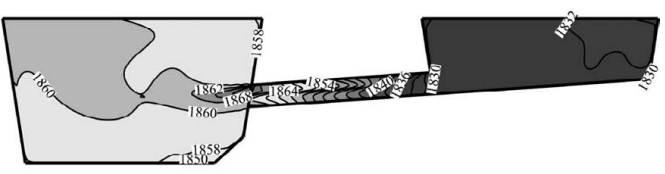

(c) $\mathrm{t}=600 \mathrm{~s}$

Fig. 16. Temperature distribution at the vertical section of tundish with $1000 \mathrm{~kW}$ induction heating power.

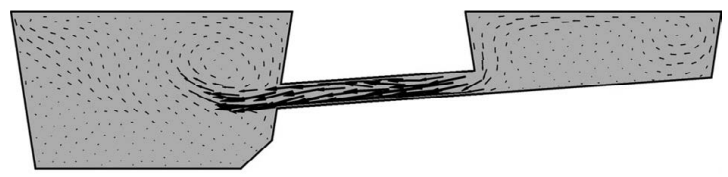

(a) $\mathrm{t}=200 \mathrm{~s}$

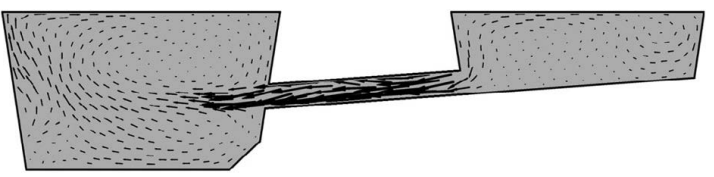

(b) $\mathrm{t}^{-}-400 \mathrm{~s}$

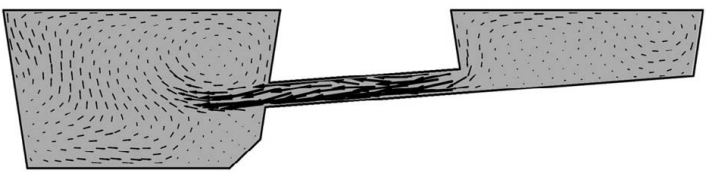

(c) $\mathrm{t}=600 \mathrm{~s}$

Fig. 17. Velocity field at the vertical section of tundish with $1000 \mathrm{~kW}$ induction heating power: maximum velocity is $0.2324 \mathrm{~m} / \mathrm{s}$.

Figure 20 shows the outlet temperature of molten steel with different induction heating power. The outlet temperature of molten steel has a tendency of stability after $800 \mathrm{~s}$ with different induction heating power. The stable outlet temperature of molten steel turns higher with increasing induction heating power. Thus, the rate of temperature rising in the tundish with $800 \mathrm{~kW}, 1000 \mathrm{~kW}$ and $1200 \mathrm{~kW}$ is 0.975 $\mathrm{K} / \mathrm{min}, 1.875 \mathrm{~K} / \mathrm{min}$ and $2.625 \mathrm{~K} / \mathrm{min}$. The induction heating regulation can be developed according to the rate of temperature rising with different induction heating power.

\subsection{Distribution of the Tracer Concentration}

A user defined non-dimensional scalar is used to investigate the distribution of molten steel compositions in tundish without and with induction heating. The stable distribution of the tracer concentration is shown in Fig. 21. The distribution of the tracer concentration is very nonuniform in the tundish without induction heating. In the region close to the outlet of the channels, the tracer concentration is highest and then reduces dramatically in surrounding region. The minimum tracer concentration appears in the lower region of the discharging chamber. The tracer concentration difference is about 0.096 . The dead zone and the nonuniform temperature distribution are responsible for it.

Figures 21(b) to 21(d) shows the distribution of the tracer concentration in the tundish with different induction heating power. With the help of induction heating, the tracer is mixed more efficiently. The distribution of the tracer concentration

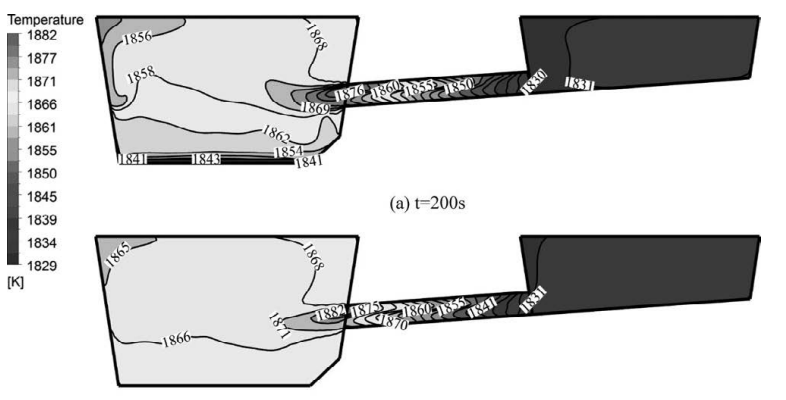

(b) $t=400 s$

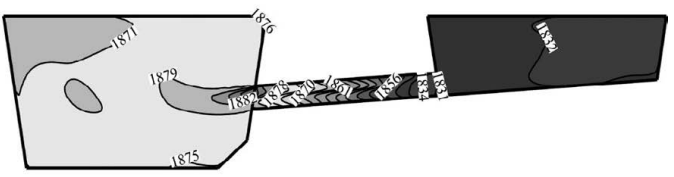

(c) $\mathrm{t}=600 \mathrm{~s}$

Fig. 18. Temperature distribution at the vertical section of tundish with $1200 \mathrm{~kW}$ induction heating power.

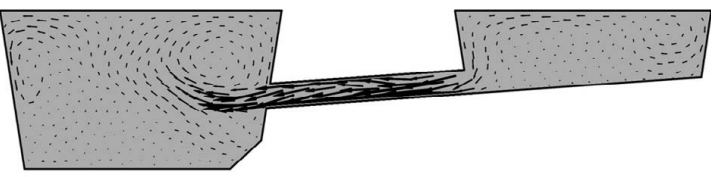

(a) $\mathrm{t}=200 \mathrm{~s}$

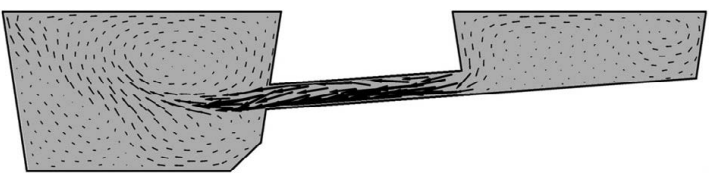

(b) $\mathrm{t}=400 \mathrm{~s}$

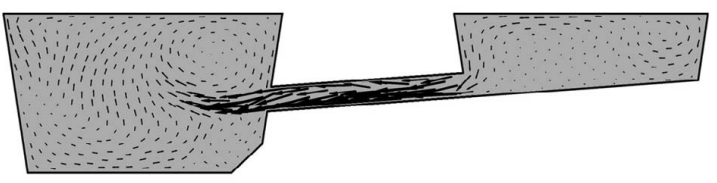

(c) $\mathrm{t}=600 \mathrm{~s}$

Fig. 19. Velocity field at the vertical section of tundish with $1200 \mathrm{~kW}$ induction heating power: maximum velocity is $0.2642 \mathrm{~m} / \mathrm{s}$

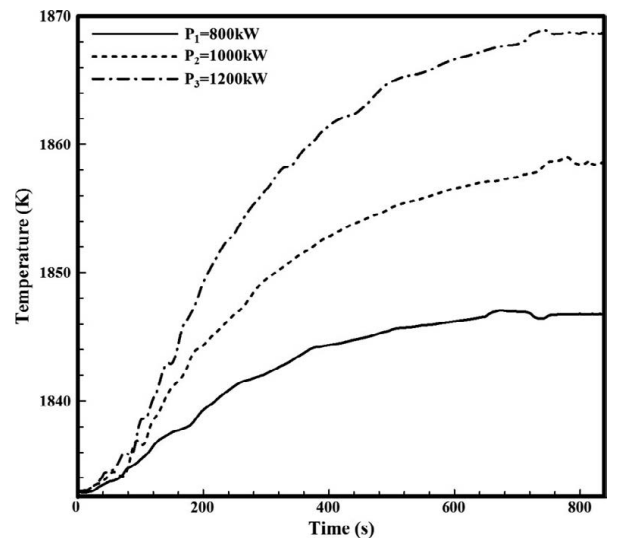

Fig. 20. Outlet temperature of the molten steel with different induction heating power.

gets more uniform. The tracer concentration difference decreases with the increasing of induction heating power. The minimum tracer concentration in the tundish with $1200 \mathrm{~kW}$ induction heating is 0.948 . The tracer concentration difference is about 0.052 which reduces by $46 \%$ approximately comparing with that in the tundish without induction heating. From above results, it is clear that the induction heating is beneficial to the molten steel compositions uniformity. 


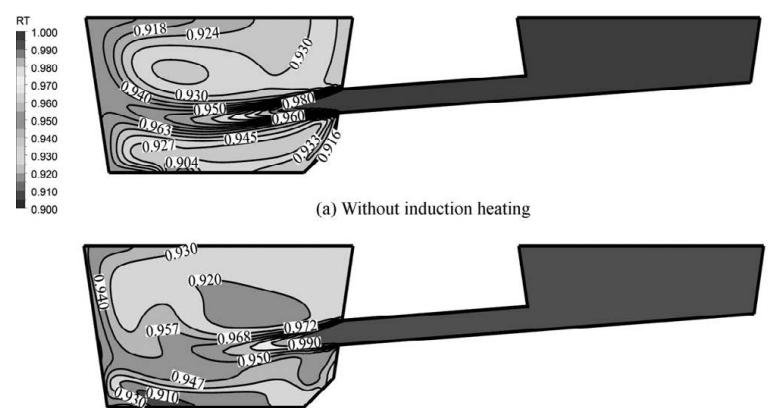

(b) With $800 \mathrm{~kW}$ induction heating power

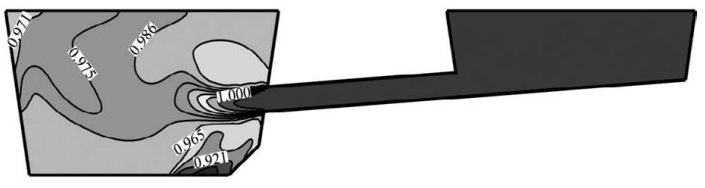

(c) With $1000 \mathrm{~kW}$ induction heating powe

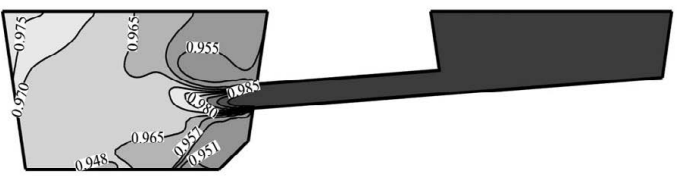

(d) With $1200 \mathrm{~kW}$ induction heating powe

Fig. 21. Distribution of the tracer concentration at the vertical section of tundish at the time of $600 \mathrm{~s}$.

\section{Conclusions}

A thermo-electromagneto-hydrodynamic model was developed to investigate the multi-physical field in the continuous casting tundish with induction heating. The following results were obtained:

(1) A current loop would be formed by the induced current through the channels. The induced current distributes at the channel and the two chambers near the induction coil mainly. The magnetic flux density in the channels and the two chambers near the induction coil is much greater than that in the other regions. It is a rotating magnetic field in the channels.

(2) Electromagnetic force would be generated as a result of the interaction of magnetic field with the induced current. The distribution of the electromagnetic force is asymmetrical in the channels. Therefore, the molten steel has a rotating velocity when flows past the channels due to the off-center force. In addition, the electromagnetic force points to the center of the channels which would generate a pinch effect on the molten steel.

(3) The interaction of induced current with molten steel produces joule heating which can heat the molten steel effectively. The distribution of joule heating is roughly as same as the distribution of induced current. The molten steel lifts upward after flows past the channels in the tundish with induction heating under the effect of buoyancy. This motion mode of molten steel reduces the short-circuit flow and prolongs the residence time.

(4) The dead zone and the low temperature region reduce ignificantly in the tundish with induction heating. Therefore, the temperature distribution turns more uniform which is beneficial to the molten steel compositions uniformity. In addition, the outlet temperature can be controlled accurately with induction heating which is easier to keep a constant casting temperature during continuous casting process. It is obvious to see that the cast slab quality can be improved with induction heating.

\section{Acknowledgements}

Authors are grateful to the National Natural Science
Foundation of China and Baosteel Co., Ltd. For supporting this research, Grant No. 50934008.

\section{REFERENCES}

1) L. C. Zhong, B. K. Li, Y. X. Zhu, R. G. Wang, W. Z. Wang and X. J. Zhang: ISIJ Int., 47 (2007), 88.

2) P. K. Jha, P. S. Rao and A. Dewan: ISIJ Int., 48 (2008), 154.

3) V. Singh, A. R. Pal and P. Panigrahi: ISIJ Int., 48 (2008), 430.

4) Y. Tsukaguchi, O. Nakamura, P. Jonsson, S. Yokoya, T. Tanaka and S. Hara: ISIJ Int., 47 (2007), 1436.

5) K. Chattopadhyay, M. Isac and R. I. L. Guthrie: ISIJ Int., 52 (2012), 2026.

6) S. F. Yang, L. F. Zhang, J. S. Li and K. Peaslee: ISIJ Int., 49 (2009), 1551.

7) T. Ueda, A. Ohara and M. Sakurai: EU Patent, 84301814.4, (1984).

8) M. Mabuchi, Y. Yoshii, T. Nozaki, Y. Kakiu, S. Kakihara and N. Ueda: ISIJ Int., 70 (1984), 118.

9) A. Umbrashko, E. Baake, B. Nacke and A. Jakovics: Metall. Mater. Trans. B, 37 (2006), 831.

10) C. Vives and R. Ricou: Proc. of 6th Int. Iron and Steel Congress, ISIJ, Tokyo, (1990), 307.

11) U. Kenji, T. Yasuji and M. Kazuhisa: Proc. of 5 th Int. Symp. on Electromagnetic Processing of Materials, ISIJ, Tokyo, (2006), 485.

12) R. Miura, R. Nisihara, H. Tanaka, Y. Takasaki and T. Imoto: ISIJ Int., 81 (1995), 30.

13) S. Joo, J. W. Han and R. I. L. Guthrie: Metall. Mater. Trans. B, 24B (1993), 767

14) S. Chakraborty and Y. Sahai: Metall. Mater. Trans. B, 23B (1992), 153.

15) D. Y. Sheng and L. Jonsson: Metall. Mater. Trans. B, 30B (1999), 979.

16) D. Y. Sheng and L. Jonsson: Metall. Mater. Trans. B, 31B (2000), 867.

17) A. Kumar, D. Mazumdar and S. C. Koria: ISIJ Int., 48 (2008), 38.

18) M. J. Cho and I. C. Kim: ISIJ Int., 46 (2006), 1416.

19) Y. Sahai and T. Emi: ISIJ Int., 36 (1996), 667.

20) Y. Sahai and R. Ahuja: Ironmaking Steelmaking, 13 (1986), 241.

21) K. Fujisaki, S. Satoh and T. Yamada: IEEE Trans. Magn., 36 (2000), 1303.

22) F. Felten, Y. Fautrelle, Y. Du Terrail and O. Metais: Appl. Math. Modell., 28 (2004), 15

23) R. Pardeshi, S. Basak, A. K. Singh, B. Basu, V. Mahashabde, S. K. Roy and S. Kumar: ISIJ Int., 44 (2004), 1534.

24) D. Mazumdar and R. I. L. Guthrie: ISIJ Int., 39 (1999), 524.

25) H. J. Odenthal, M. Javurek, M. Kirschen and N. Vogl: Steel Res. Int., 81 (2010), 529

26) X. M. Yang, S. X. Liu, J. S. Jiao, M. Zhang, J. P. Duan, L. Li and C. Z. Liu: Steel Res. Int., 83 (2012), 269.

27) B. K. Li, T. Okane and T. Umeda: Metall. Mater. Trans. B, 32 (2000), 1491.

28) Q. Hou and Z. Zou: ISIJ Int, 45 (2005), 325.

29) T. Okura, I. Ahmad, M. Kano, S. Hasebe, H. Kitada and N. Murata: ISIJ Int., 53 (2013), 76.

30) S. Sonoda, N. Murata, H. Hino, H. Kitada and M. Kano: ISIJ Int., 52 (2012), 1086.

31) J. P. Ramos, J. J. Barreto, S. Lopez-Ramirez and R. D. Morales: Ironmaking Steelmaking, 28 (2001), 101.

32) S. Chakraborty and Y. Sahai: ISIJ Int., 31 (1991), 960

33) S. Chakraborty and Y. Sahai: Ironmaking Steelmaking, 19 (1992), 479.

34) J. I. Ghojel and R. N. Ibrahim: J. Mater. Process. Tech., 153 (2004), 386.

35) B. K. Li, T. Okane and T. Umeda: Metall. Mater. Trans. B, 32 (2001), 1053.

36) Y. Wang, Y. B. Zhong, B. J. Wang, Z. S. Lei, W. L. Ren and Z. M. Ren: ISIJ Int., 49 (2009), 1542.

\section{Research Highlights}

1) First time that a non-isothermal water model experiment is performed to observe the significant buoyancy driven flow in the tundish with induction heating.

2) First time that the tracer concentration distribution in the tundish with induction heating under different input power is clarified.

3) Joule heating as well as electromagnetic force is very crucial to the metallurgical performance of the tundish with induction heating. The distribution of Joule heating as well as electromagnetic force under different input power is demonstrated in detail.

4) A coupling calculation of flow field and heat transfer is carried out. The temperature distribution in the tundish with induction heating under different input power is clarified.

5) A comprehensive mathematical model of inclusions' behavior in the tundish with induction heating would be developed in the future based on this significant work. 